white fish, such as cod, had fallen by $64 \%$ during their careers. Many fishermen blamed the declines on trawling. These largely forgotten records suggest that trawling began to affect fish stocks long before scientific monitoring and official statistics began.

Fish Fish. http://dx.doi. org/10.1111/faf.12034 (2013) For a longer story on this research, see go.nature.com $/ 5 \mathrm{rbcvq}$

\section{BIOMATERIALS}

\section{Leafy trap for bedbugs' legs}

A natural Eastern European folk remedy catches bedbugs more effectively than synthetic mimics.

Catherine Loudon at the University of California, Irvine, and her colleagues used scanning electron microscopy and videography to document why bean leaves, which are traditionally scattered around an infected bed to trap bedbugs (Cimex lectularius) are effective. Tiny hairs on the leaves, known as trichomes, trap the insects by impaling their feet and hooking their legs (pictured). The researchers designed a synthetic mimic of the hairs with a polyvinylsiloxane moulding material often used in dentistry, and a hybrid mimic made of synthetic stalks and natural trichome tips. Although both mimics snagged the bugs, they could not impale them. This suggests that a better bug trap may need to recapitulate the mechanical properties of bean leaf trichomes more closely. J. R. Soc. Interface 10, 20130174 (2013)

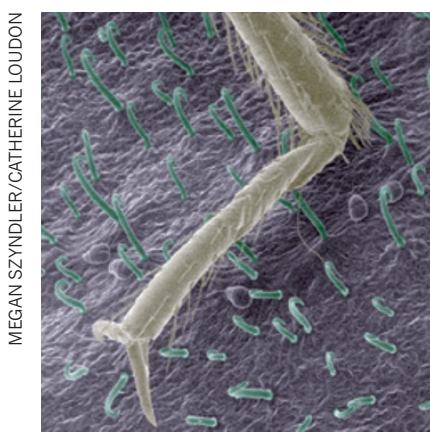

CELL BIOLOGY

\section{Super-enhancers rule genes}

The myriad biomolecules that regulate gene expression are governed by an unanticipated layer of control.

Researchers led by Richard

Young at the Massachusetts Institute of Technology in Cambridge have found assemblies of enhancers - segments of DNA that associate with regulatory proteins and attach to genes to switch them on - that they have named super-enhancers. Compared with ordinary enhancers, super-enhancers bind to more proteins that activate gene transcription and are more sensitive to perturbation. The teams found that some cancer cells assemble pathological super-enhancers.

Human cells contain tens of thousands of genes and many more enhancers, but most are controlled by only a few hundred super-enhancers that bestow characteristic properties on each cell type, the authors suggest.

Cell 153, 307-319; 320-334

(2013)

For a longer story on this research, see go.nature.com/spue $5 g$

\section{ECOLOGY}

\section{Symbionts set squid's clock}

The tick-tock of an animal's daily clock can be set, in part, by beneficial bacteria.

At night, the bacterium Vibrio fischeri glows in a compartment in the underbelly of its symbiotic host, the Hawaiian bobtail squid (Euprymna scolopes; pictured), hiding the squid's shadow in the moonlight. Margaret McFall-Ngai at the University of WisconsinMadison and her colleagues have found that the lightproducing bacteria also cause the squid to boost expression of its light-responsive gene escry 1 in the colonized

COMMUNITY CHOICE

The most viewed papers in science

\title{
Cheap, colourful solar cells
}

\section{HIGHLY READ \\ on pubs.acs.org \\ 21 Mar-18 April}

A light-harvesting crystal can make efficient, colourful and low-cost devices that convert sunlight into electricity. Researchers led by Sang Il Seok at the Korea Research Institute of Chemical Technology in Daejeon, South Korea, created metal-organic hybrid materials that were composed of lead; methylammonium; and iodine or bromine, or both. Semiconductors used in solar cells can be coated in these materials, which absorb light and displace electrons that the semiconductor transfers to an external circuit. By varying ratios of bromine and iodine, the researchers tuned the material's stability and light-absorption properties to produce solar cells with a variety of translucent colours, from dark brown to yellow. On average, the cells could convert $10 \%$ of sunlight energy into electricity, with a maximum of $12.3 \%$ - a performance that matches competing low-cost options. Nano Lett. http://dx.doi.org/10.1021/nl400349b (2013)

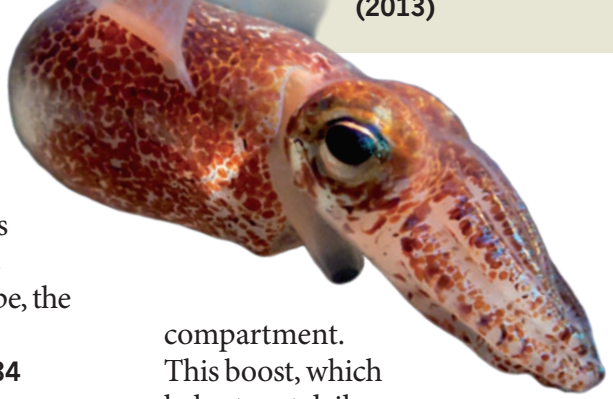

helps to set daily

rhythms, did not occur in bacteria-free squid, even if they were exposed to blue light to mimic bacterial glow. But when researchers provided squid with light as well as bits of the bacterium's cell envelope, escry1 cycling returned.

The researchers suggest that microbiota could also set daily rhythms in mammals.

mBio 4, e00167-13 (2013)

\section{MMUNOLOGY}

\section{Proteins that} rouse also quash

Signalling pathways that initially orchestrate potent antiviral attacks can, paradoxically, also help to sustain chronic infections.

Proteins called type I interferons (IFN-I) curb viral replication during early stages of infection, but are unable to clear chronic infections. To solve this longstanding puzzle, independent groups led by David Brooks at the University of California, Los Angeles, and Michael Oldstone at the Scripps Research Institute in La Jolla, California, studied mice infected with strains of lymphocytic choriomeningitis virus that cause chronic infection.

Both groups found that IFN-I produces an initial burst of antiviral activity, but then depresses the immune system over the long term, allowing the virus to persist.

Chronic activation of the immune system can damage tissue, and the authors speculate that IFN-I signalling dampens the immune-system response to limit this damage. Inhibiting IFN-I signalling may help to control chronic viral infections, they say.

Science 340, 202-207; 207-211 (2013)

\section{DNATURE.COM}

For the latest research published by Naturevisit:

www.nature,com/latestresearch 